\title{
Technological innovations in the production of sportwear: from conventional production to Industry 4.0
}

\author{
Adriana Yumi Sato Duarte ${ }^{a, b, c}$, Regina Aparecida Sanches ${ }^{b}$, Fernando Soares de Limac, Rayana Santiago de Queiróz ${ }^{c}$, \\ Franco Giuseppe Dedinid \\ a Centro Universitário Nossa Senhora do Patrocínio - CEUNSP, Salto, SP, Brasil \\ ${ }^{b}$ Escola de Artes, Ciências e Humanidades, Universidade de São Paulo - EACH, Universidade de São Paulo - USP, São Paulo, SP, Brasil \\ ' Instituto de Pesquisas Tecnológicas - IPT, São Paulo, SP, Brasil \\ d Faculdade de Engenharia Mecânica - FEM, Universidade Estadual de Campinas - UNICAMP, Campinas, SP, Brasil \\ e-mails: adriana.duarte@ceunsp.edu.br; regina.sanches@usp.br; nandos@@ipt.br; rayanasq@ipt.br; dedini@fem.unicamp.br
}

\begin{abstract}
The present research aims to present the technological evolution of sportwear production by comparing conventional and new production systems. For this, the following production systems were defined: conventional knitting (T-shirt and shoe upper), seamless knitting (T-shirt) and seamless 3D knitting (shoe upper). The definition of these objects of study was based on research that points to walking as the most practiced physical activity by Brazilians. The methodological procedure adopted in the present research is predominantly exploratory. Sportwear can be produced by the conventional process or new production processes. In the conventional production process, there are many steps for fabric manufacturing and confection. In turn, seamless technology reduces working time by creating ready-to-wear articles that require little or no sew, since the product is developed in a single process. In this way, seamless technology impacts on working time by reducing or eliminating the cut and sew operations and the amount of waste discarded. All innovations presented in this research indicate efficient production related to cost, working time, waste management and interaction with the consumer. By adopting these technologies, the textile industry begins to move towards the Fourth Industrial Revolution.
\end{abstract}

Keywords: sportwear, knitting, seamless, textile and apparel chain.

\section{Introduction}

The Textile and Apparel chain played - and still plays an important role in the history of industrialization in the world. Unlike other value-added chains, it includes a large number of process steps performed by different successive industrial units, including: (i) fiber production; (ii) spinning; (iii) weaving/knitting; (iv) garment production process; (v) merchandising; (vi) retail sales; (vii) consumption; and (viii) disposal/recycling (Tobler-Rohr, 2011).

Among the different textile and apparel products, the sportwear represents a great exponent in the world economy and in technological development. The sportwear combines the concepts of functionality, comfort, and safety to meet the performance of each athlete in sport. Sport articles include clothing, footwear and accessories used for both competitive and leisure activities.

In this context, the present research aims to present the technological evolution of sportwear production by comparing conventional and new production systems. For this, the following production systems were defined: conventional knitting (T-shirt and shoe upper), seamless knitting (T-shirt) and seamless 3D knitting (shoe upper).

The definition of these objects of study was based on research that points to walking as the most practiced physical activity by Brazilians (Instituto Brasileiro de Geografia e Estatística, 2013; Brasil, 2018). The methodological procedure adopted in the present research is predominantly exploratory.

\section{Research background}

\subsection{Textile and apparel chain}

The Textile and Apparel Chain consists of fiber production, spinning, weaving or knitting, garment production processes, merchandising, retail and sales, consumption and pos-consumption. In 2013, the textile and clothing exportation corresponded to US $\$ 766$ billion, China was the leader in exports of both textiles (39\%) and clothing (35\%), while the European Union was the largest importer (38\%). By 2020, this volume should increase to 
US\$ 851 billion (Associação Brasileira da Indústria Têxtil e de Confecção, 2014).

Brazil is the fifth largest textile industry in the world, the fourth in clothing and the fifth in cotton production. However, in a global context, the Brazilian industry share represents less than $0.4 \%$ of this market. This sector was responsible for the emergence of many other industries and it is historically linked to the industrial revolution in Brazil. Currently, the Textile and Apparel Chain employs almost 2 million people directly (Associação Brasileira da Indústria Têxtil e de Confecção, 2014).

In Brazil, there are different textile production hubs concentrated in the South, Southeast and Northeast regions. The South region, which covers the states of Paraná, Santa Catarina and Rio Grande do Sul, concentrates the knitting production and bed and bath articles. In terms of technology, this region is one of the most advanced centers in the country. The production of the Northeast region is concentrated in denim (jeans), cotton fabrics and polyester yarns, mainly in the states of Ceará and Pernambuco. The Southeast region is the largest textile production hub in Brazil with a great diversity of articles. The State of Rio de Janeiro concentrates the production of underwear, beachwear and sportswear. Minas Gerais presents industrial districts for spinning and knitting of cotton articles. The State of São Paulo concentrates the largest confections and retail centers in the country. The textile industries represent $29 \%$ of the country production (IEMI, 2014; Sinditêxtil, 2011; Obiettivo Brasil, 2016).

\subsection{Textile and apparel chain: from the first to the Fourth Industrial Revolution}

The First Industrial Revolution was particularly important for the textile industry. In 1733, John Kay patented his flying shuttle propelled by a cord that increased consumption of items produced in looms. In 1764, James Hargreaves invented the Spinning Jenny, a spinning machine that replaced the manual method of yarn production. Joseph-Marie Jacquard, in 1801, combined different existing mechanisms to develop the Jacquard Loom (McNeil, 2002).

The transition to the Second Industrial Revolution occurred between 1840 and 1870 and had as main catalyst the use of electricity for mass production (Schuh et al., 2014; Sabo, 2015). John Thorp created a new method of spinning in 1828: the Ring Frame. In addition, the first circular knitting machine was patented in 1816 (McNeil, 2002). A few years later, in 1847, the tubular fabric became popular thanks to the Rib pattern, the most used in sweaters, socks, collars and cuffs (Frings, 2012). In 1856, Matthew Townsen invented the latch needle which simplified the production of knitwear. In 1864, William Cotton adapted a mechanical propulsion machine capable of knitting several socks at the same time. One of the first mass-produced consumer goods was the sewing machine that dramatically changed the consumption and production of clothes. As a result, this sewing machine was adapted for other segments, such as footwear (McNeil, 2002).

The Third Industrial Revolution, also known as the digital revolution, is focused on the transition from analogue to digital technology, having as ultimate symbol the invention of integrated circuits that allow increasing computational capacity and decreasing production costs. As a result, the industry widely adapted itself to information technology (IT) and has a significant impact on the growth of economic performance until the present day (Schuh et al., 2014). Some technological solutions, such as 3D scanning, $3 \mathrm{D}$ modeling and digital printing are gradually being adopted by the textile industry (McNeil, 2002).

The Fourth Industrial Revolution - also called Industry 4.0 - advocates the need for connection between all information flows throughout the production process, in an autonomous production system that allows for fast and flexible production (Gloy et al., 2013). Industry 4.0 is a collective term for technologies and concepts in the value chain of an intelligent factory that monitor production processes (Anderl, 2015). Intelligent machines that anticipate the occurrence of failures or quality problems in the production process and organize the decision and selfoptimization processes are other scenarios for Industry 4.0 (Gölzer et al., 2015).

\subsection{Sportwear: materials and production processes}

The sportwear combines functionality, comfort, and safety to meet the performance of each athlete. Sport articles include clothing, footwear and accessories used for both competitive and leisure activities (Campaniaris et al., 2011).

This segment presents a great impact in the global economy. In 2017, sales in the sports retail sector corresponded to US\$ 260 billion. The global market has evolved a lot in the last decades, mainly from the 1980s influenced by the wellness and fitness lifestyle and the professionalization and dissemination of the sport (Sports Value, 2018).

Due to the great variety of sports, sport articles are developed to favor the performance of the practitioner. In this sense, the raw material, yarn and fabric production, confection and chemical finishing are fundamental to meet the practitioner needs and sport requirements (Filgueiras et al., 2007).

Functional elements can be applied to textile products in three moments: (1) in fiber, through new production techniques; (2) in the yarn, by creating new structures; and (3) in the fabric, with surface modifications (Soutinho, 2006; Morent \& De Geyter, 2011). 
Knitting is the fabric production technique which allows greater elasticity and adjustment to the body and provide freedom of movement. Knitted fabric consists of loops that connect to each other, in the same direction (Figure 1), with mobile connection points, from mechanical needle movements (Liu et al., 2017).

Different types of machines, structures, stitches, yarns and needle sizes can be used to create fabrics (Zhang \& Ma, 2018). In addition to clothing, the knitted fabric is also applied to the shoe upper, the portion of the shoe that encases the foot, as shown in Figure 2.

\section{Objects of study: description and analysis}

\subsection{Textile product: Sport T-shirt}

The conventional kitting process takes place with the use of only one yarn that can feed all the needles of the machine due to its evolution in the horizontal direction in the large diameter circular knitting machines, as shown in Figure 3.

These machines produce a continuous tubular fabric, with different characteristics and a high production volume. The fabric involves three macro phases: (1) textile yarns selection; (2) knitting process and (3) finishing. The T-shirt confection includes cutting, sewing, finishing and revision of the article, packaging, and stock (Carmelo Comercial, 2019). Figure 4 summarizes these phases.

A knitting technological innovation is the seamless knitting. Seamless is the term for a knitted apparel with tubular structure constructed in a single piece with minimal or no cutting and sewing processes (Lau \& Yu, 2016). This technology emerged in the 1980s to provide greater comfort to the user by producing a piece that molded to the body. This production system is widely used for underwear, sportswear, casual fashion and technical textiles (Nawaz \& Nayak, 2015; Magnus et al., 2010).

Seamless technology reduces work time by creating pieces that are ready-to-wear, requiring little or no sewing, dramatically reducing labor intensive use. In addition, there is a reduction in material losses and in the finishing stages (Sayer et al., 2006). The seamless machine is composed of needles, wire guides, actuators, selectors that are electronically controlled (Carmelo Comercial, 2019). Seamless production joins the stages of fabric production, cutting and sewing, as shown in Figure 5.

\subsection{Textile product: knitted shoe upper}

Footwear is one of the interfaces between foot and floor. For sports shoes, in particular, two factors must be taken into account: (1) the prevention of excessive loads that act on the structures of the human body, and (2) the improvement of performance in sports activity (Cardoso et al., 2019).

In addition, comfort and breathability are closely related to the material and weight of the shoes. Lu et al.(2016)

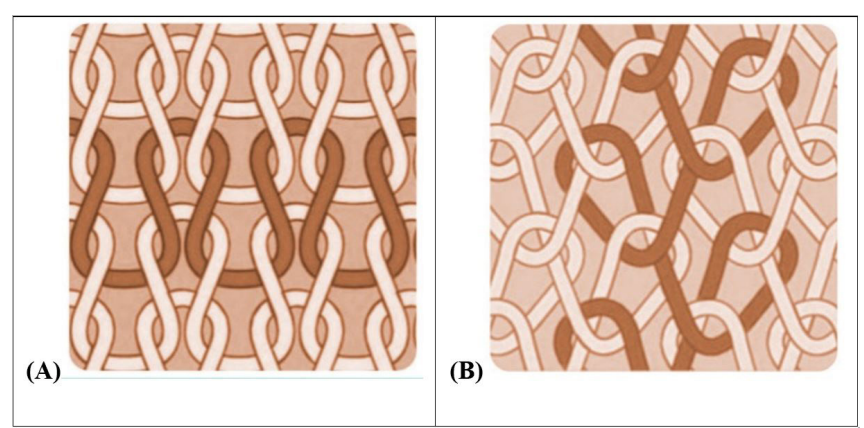

Figure 1. Weft (A) and warp (B) knitting. Source: Authors.

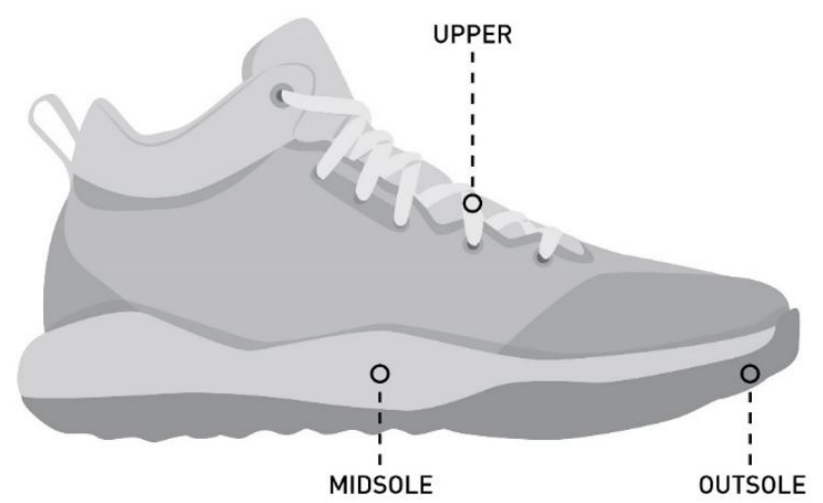

Figure 2. Shoe upper. Source: Diks Protips (2020).

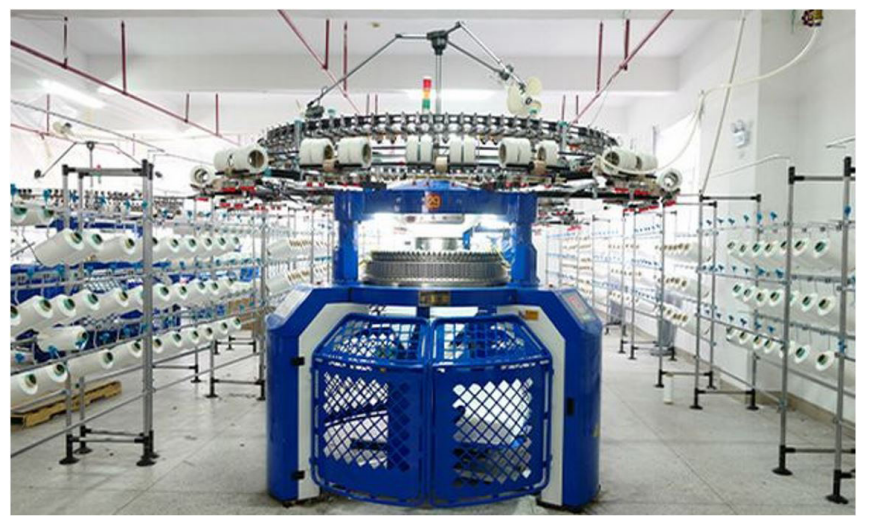

Figure 3. Large diameter circular knitting machine. Source: Modern Life (2017).

affirm that the lighter the weight of the shoes, the greater the comfort and point out that an increase of $1 \%$ in the weight of the shoes consumes $3 \%$ to $10 \%$ more energy when walking. The shoe upper plays a wrapping and protective role for the feet in sports activity.

Conventional shoe upper production consists of warp knitted fabric, processing the fabric (dyeing and finishing), cutting, visual inspection, embroidering, armor transfer, insole transfer, backstitch/sewing, conformation and assembly (1), as summarized in Figure 6. 


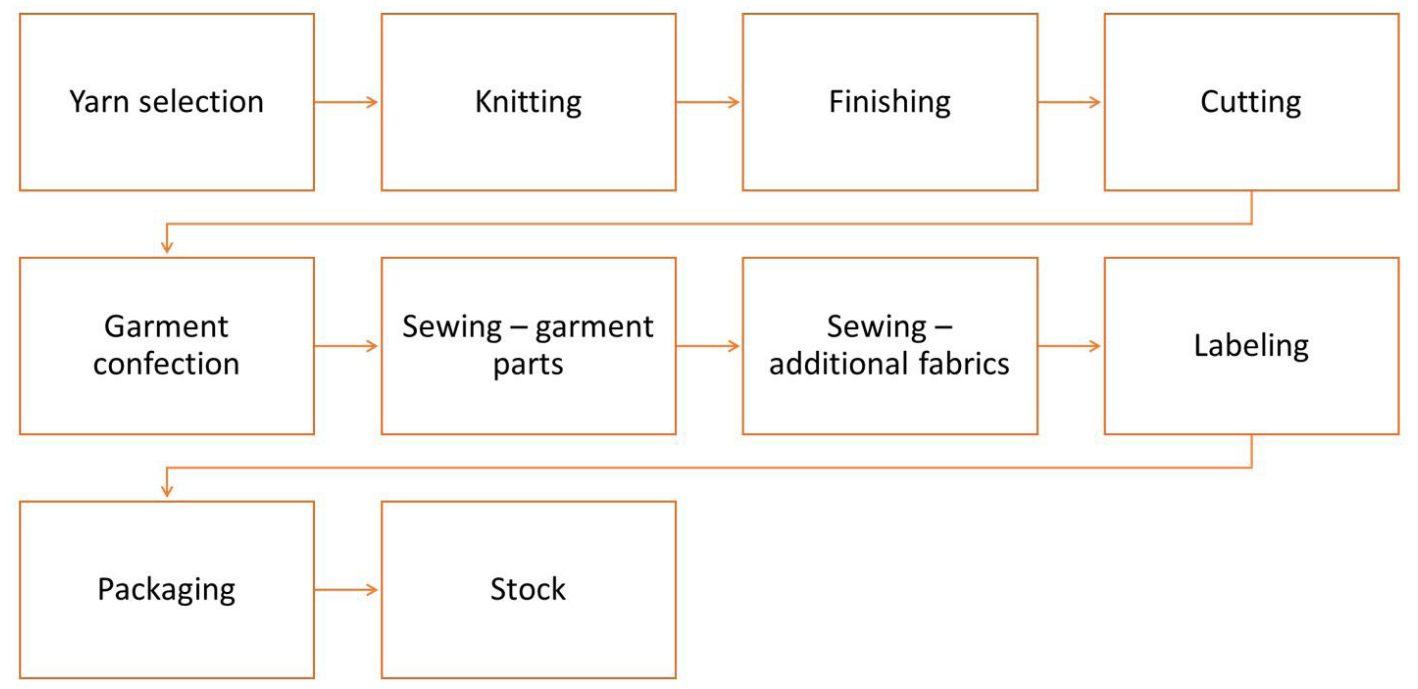

Figure 4. Conventional knitting process - T-shirt. Source: Authors.

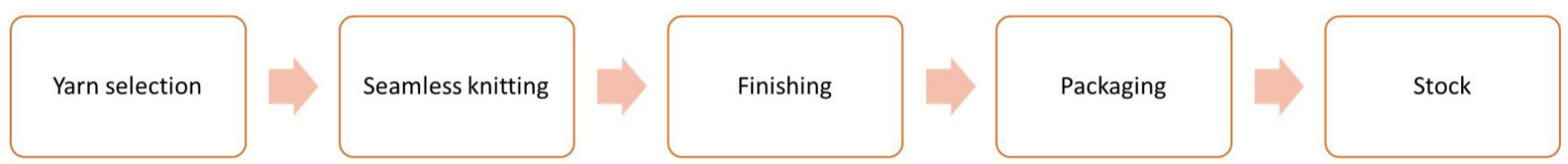

Figure 5. Seamless knitting process - T-shirt. Source: Authors.

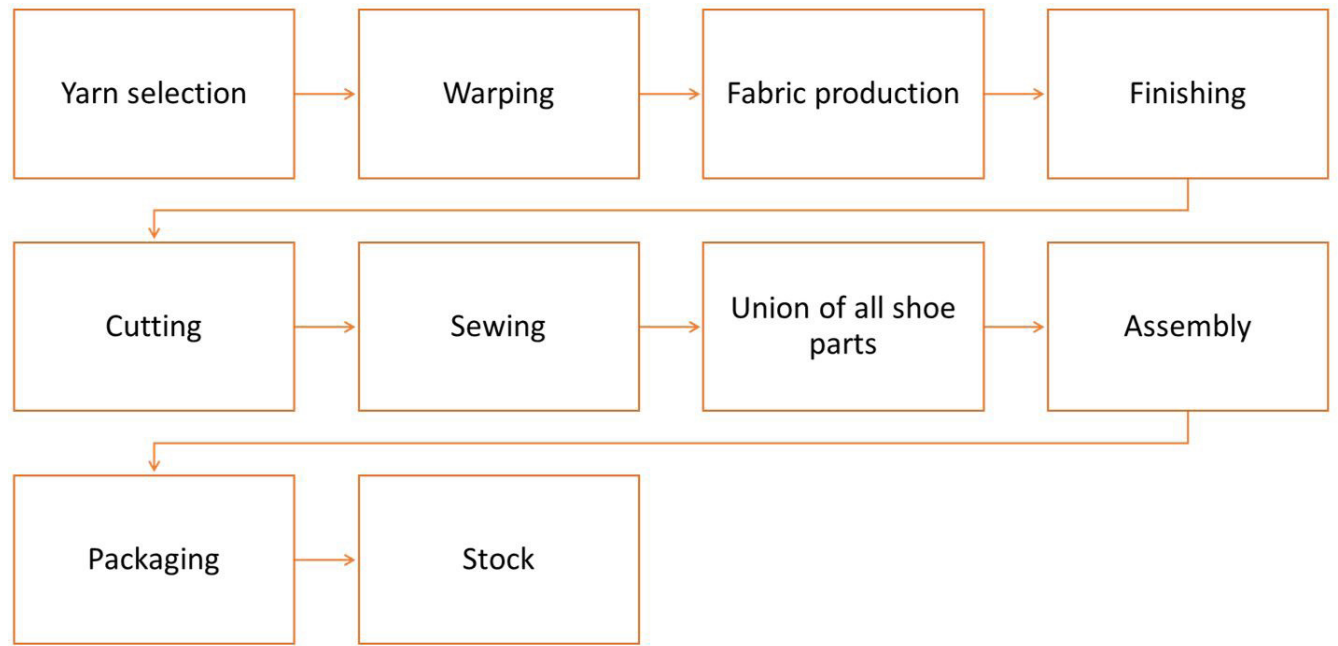

Figure 6. Conventional knitting process - shoe upper. Source: Authors.

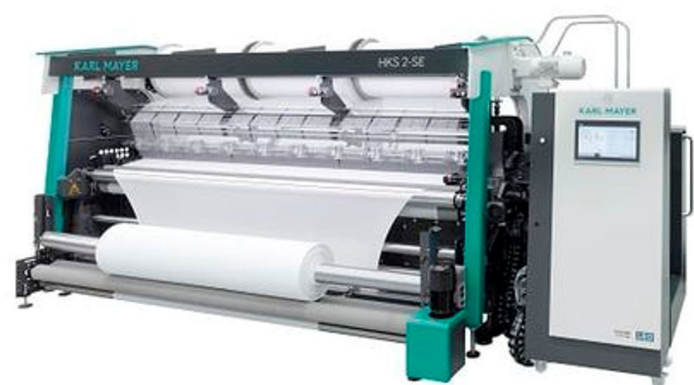

Figure 7. Kettenstuhl Loom. Source: Karl Mayer (2019).
This fabric can be produced on a warp loom with two or more bars (Figure 7), which can be integrated with other layers of mesh. Old looms have nozzle needles and are slower, modern looms have composite needles and are high speed. For the weave of the mesh, the needles go up, receive a new yarn from the dowels, and go down to form a mesh (Spencer, 2001).

As in the production of the T-shirt, the seamless technology can be used in the production of the shoe upper (Figure 8), eliminating the steps of cutting and sewing, 


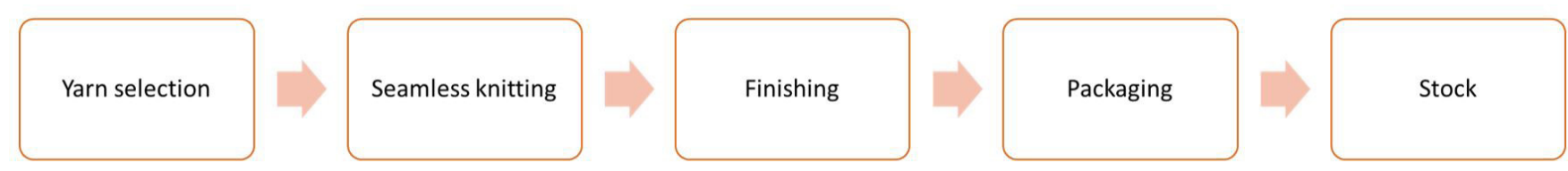

Figure 8. Seamless knitting process - shoe upper. Source: Authors.

resulting in the $3 \mathrm{D}$ knitting. This technology produces a piece ready for the sole application (Knitting Industry, 2018).

\section{Objects of study: discussion and comparison between conventional and seamless knitting}

In general terms - both in conventional and seamless production - it is noticed that the fabric production's principle has not significantly changed. Therefore, technological innovations are related to improve machine elements and production systems, such as new types of needles, techniques to transfer the meshes from one needle track to another, high-speed production, and unlimited patterns creation.

In sportwear case, technological innovation - specially the seamless technology - can transform mass production to mass customization. This industrial sector is characterized by a high consumer demand associated with an expectation of customized and fashionable products.

Mass customization refers to a production strategy that includes planning, design, production, and services that achieve the diverse consumers' needs without compromising the economy of scale of a company. The mass customization presupposes a user experience, which encompasses all aspects of the end-user's interaction with the company; however, it is necessary to adopt a flexible manufacturing system that meets the most dispersed orders (Zhang et al., 2019).

Intelligent design for customized products is a trend (Zhang et al., 2017). In addition to the technological innovation, the product development process should include style references (colors, pattern), comfort (sizes, formats, materials) and individual's context (culture, social habits, preferences).

Based on the comparison between conventional an seamless knitted fabric, the seamless technology suggests: (1) simplification of production process by reducing costs, increasing production and reducing errors; (2) reduction in quantity of production stages and machinery; and (3) creation of different products in a single process (Tsai \& Jhong, 2019).

Although the positive aspects previously mentioned, there are challenges to implementing technological innovations in textile industry. First, it is important to integrate expertise, such as design, engineering, computer science, mechatronics. In companies, business models and shop floor, the challenges are related to (1) the social and economic impacts of the loss of many current jobs, due to the replacement of manual labor by automation; (2) the cost of acquisition and implementation of technology, especially for small and medium-sized companies; and, (3) digital security, a robust security protocol is needed to protect confidential information (Kamble et al., 2018).

\section{Conclusions}

Since the First Industrial Revolution, there have been modifications in the production-consumption and in the organization of society. In the contemporary competitive context, technological tools, the need for a rapid response in the decision-making process, the demand for functional products and the appropriate social and environmental responsibilities of organizations are fundamental principles for the development of new products. The First Industrial Revolution allowed the mechanization of the productive process and stimulated consumption and the need for constant renewal of the products. The Second Industrial Revolution introduced new sources of energy, mass production and the revolution of consumer goods. The Third Industrial Revolution was characterized by the transition from analog to digital and by the segmentation of consumer markets. The Fourth Industrial Revolution, which is the one currently taking place, is based on the integrative and collaborative environment, on the adoption digital tools and on the active role of consumers in the production system.

Sportwear can be produced by the conventional process or new production processes. In the conventional production process, there are many steps for fabric manufacturing and confection. In turn, seamless technology reduces working time by creating ready-to-wear articles that require little or no sew, since the product is developed in a single process. In this way, seamless technology impacts on working time by reducing or eliminating the cut and sew operations and the amount of waste discarded. All innovations presented in this research indicate efficient production related to cost, working time, waste management and interaction with the consumer. By adopting these technologies, the textile industry begins to move towards the Fourth Industrial Revolution. 


\section{References}

Anderl, R. (2015). Industrie 4.0 - technological approaches, use cases, and implementation. at-Automatisierungstech., v. 63 , n. 10 , p. $753-765$.

Associação Brasileira da Indústria Têxtil e de Confecção (ABIT). (2014). Agenda de Prioridades Têxtil e Confecção -2015/2018. São Paulo: ABIT.

Brasil. Ministério da Saúde, Secretaria de Vigilância em Saúde. (2018). Vigitel Brasil 2017: vigilância de fatores de risco e proteção para doenças crônicas por inquérito telefônico. Brasília.

Cardoso, H., Guimarães, M., Lopes, L., \& Lino Alves, J. (2019). Development of a rubber sole with an integral cushioning system for casual sport shoes. Proceedings of the Institution of Mechanical Engineers, Part L: Journal of Materials: Design and Applications, 233(11), 2253-2266.

Carmelo Comercial. (2019). A tecnologia seamless (18 p.). São Paulo.

Diks Protips. (2020). How to buy basketball shoes. Retrieved in 2020, May 26, from https://protips.dickssportinggoods.com/ sports-and-activities/basketball/buying-basketball-shoes

Filgueiras, A., Fangueiro, R., \& Raphaelli, N. (2007). A importância de fibras e fios no design de têxteis destinados à prática desportiva. Estudos em Design, 15(1), 1-20.

Frings, G.S. (2012). Moda: do conceito ao consumidor. Porto Alegre: Bookman Editora.

Gloy, Y. S., Schwarz, A., \& Thomas, G. (2013, September). Cyber-physical systems in textile production, the next industrial revolution. In Proceedings of the 1st International Conference on Digital Technologies for the Textile Industry (pp. 1-12). TexEng Software.

Gölzer, P., Cato, P., \& Amberg, M. (2015, May). Data processing requirements of Industry 4.0: use cases for big data applications. In Proceedings of the European Conference on Information Systems (ECIS). Münster, Germany: ECIS.

Hayes, S., Jeffrey, M., Murray, R. (2011). The applicability of cluster theory to Canada small and medium sized apparel companies. Journal Of Fashion Marketing And Management, 8-26.

IEMI. (2017). São Paulo Têxtil 2014: relatório setorial da indústria têxtil e confecção no Estado de São Paulo. São Paulo: IEMI.

Instituto Brasileiro de Geografia e Estatística - IBGE. (2013). Diagnóstico Nacional do Esporte: a prática do esporte no Brasil. Rio de Janeiro.

Kamble, S. S., Gunasekaran, A., \& Sharma, R. (2018). Analysis of the driving and dependence power of barriers to adopt industry 4.0 in Indian manufacturing industry. Computers in Industry, 101, 107-119. http://dx.doi.org/10.1016/j. compind.2018.06.004.

Karl Mayer. (2019). Retrieved in 2019, June 28, from https:// www.karlmayer.com

Knitting Industry. (2018). Retrieved in 2019, June 28, from https://www.knittingindustry.com/hosiery-seamless/ santoni-introduces-X-machine-for-footwear/

Lau, F., \& Yu, W. (2016). Seamless knitting of intimate apparel. In Advances in Women's Intimate Apparel Technology (pp. 55-68). Woodhead Publishing.http://dx.doi.org/10.1016/ B978-1-78242-369-0.00004-9.

Liu, D., Christe, D., Shakibajahromi, B., Knittel, C., Castaneda, N., Breen, D., Dion, G., \& Kontsos, A. (2017). On the role of material architecture in the mechanical behavior of knitted textiles. International Journal of Solids and Structures, 109, 101-111. http://dx.doi.org/10.1016/j.ijsolstr.2017.01.011.

Lu, Z., Jiang, G., Cong, H., \& Yang, X. (2016). The Development of the flat-knitted shaped uppers based on ergonomics. AUTEX Research Journal, 16(2), 67-74.

Magnus, E. B., Broega, A. C., \& Catarino, A. P. (2010, October). Tecnologia seamless: perspectivas futuras. In Anais do $9^{\circ}$ Congresso Brasileiro de Pesquisa e Desenvolvimento em Design. São Paulo.

McNeil, I. (Ed.). (2002). An encyclopedia of the history of technology. New York: Routledge.

Modern Life. (2017). Retrieved in 2019, June 28, from https:// www.modernlifeblogs.com/2017/08/can-circular-knittingmachines-contribute-sewing-industry/

Morent, R., \& De Geyter, N. (2011). Improved textile functionality through surface modifications. In N. Pan \& G. Sun (Eds.), Functional textiles for improved performance, protection and health (pp. 3-26). Woodhead Publishing.

Nawaz, N., \& Nayak, R. (2015). Seamless garments. In R. Nayak \& R. Padhye (Eds.), Garment manufacturing technology (pp. 373-383). Cambridge: Woodhead Publishing.

Obiettivobrasil. (2017/01/16). O setor têxtil no Brasil. From: http://www.obiettivobrasil.com.br/pt-BR/news/ pesquisas $/ \mathrm{O} \% 20$ setor $\% 20 \mathrm{t} \% \mathrm{C} 3 \% \mathrm{AAxtil} \% 20 \mathrm{no} \% 20 \mathrm{Brasil}$

Sabo, F. (2015). Industry 4.0 - a comparison of the status in Europe and the USA. Austrian Marshall Plan Foundation, Austria.

Sayer, K., Wilson, J., \& Challis, S. (2006). Seamless knitwear: the design skills gap. The Design Journal, 9(2), 39-51.

Schuh, G., Potente, T., Varandani, R., Hausberg, C., Fränken, B. (2014). Collaboration moves productivity to the next level. Procedia CIRP 17 (3-8). 
Sinditêxtil. (2011). Estudo faz radiografia do setor têxtil paulista. São Paulo: Sinditêxtil.

Soutinho, H. F. C. (2006). Vestuário desportivo: novos desenvolvimentos e novas funcionalidades [Doctoral Dissertation]. Departamento de Engenharia Têxtil, Universidade do Minho, Guimarães, Portugal.

Spencer, D. J. (2001). Knitting technology: a comprehensive handbook and practical guide. Cambridge: Woodhead Publishing.

Sports Value. (2018). Retrieved in 2019, May 5, from https:// www.sportsvalue.com.br/estudos/competicao-global-dasmarcas-de-material-esportivo/

Stoll. (2019). Retrieved in 2019, June 8, from https://www. stoll.com/en/machines/knitwear/
Tobler-Rohr, M.I. (2011). Handbook of sustainable textile production. UK: Woodhead Publishing.

Tsai, W. H., \& Jhong, S. Y. (2019). Production decision model with carbon tax for the knitted footwear industry under activity-based costing. Journal of Cleaner Production, 207, 1150-1162.

Zhang, C., Chen, D., Tao, F., \& Liu, A. (2019). Data driven smart customization. Procedia CIRP, 81, 564-569.

Zhang, S., Xu, J., Gou, H., \& Tan, J. (2017). A research review on the key technologies of intelligent design for customized products. Engineering, 3(5), 631-640.

Zhang, X., \& Ma, P. (2018). Application of knitting structure textiles in medical areas. AUTEX Research Journal, 18(2), 181-191. 